\title{
EDITORIAL
}

\section{Androgen hazards with COVID-19}

\author{
Nima Sharifi1 1,2,3 and Charles J Ryan ${ }^{4,5}$ \\ ${ }^{1}$ Genitourinary Malignancies Research Center, Lerner Research Institute, Cleveland Clinic, Cleveland, Ohio, USA \\ 2Department of Urology, Glickman Urological and Kidney Institute, Cleveland Clinic, Cleveland, Ohio, USA \\ 3Department of Hematology and Oncology, Taussig Cancer Institute, Cleveland Clinic, Cleveland, Ohio, USA \\ 4Division of Hematology, Oncology and Transplantation, University of Minnesota Medical School, Minneapolis, Minnesota, USA \\ ${ }^{5}$ Masonic Comprehensive Cancer Center, Minneapolis, Minnesota, USA
}

Correspondence should be addressed to N Sharifi: sharifn@ccf.org

The emergence of severe acute respiratory syndrome coronavirus 2 (SARS-CoV-2) in December 2019 spurred the coronavirus disease 2019 (COVID-19) pandemic. A notable finding in many affected countries is that men have worse clinical outcomes and COVID-19 deaths compared with women (Grasselli et al. 2020, Moalem 2020). Sex differences in smoking do not appear to account for poorer outcomes (Cai 2020). Why then are there worse clinical outcomes for men compared with women? Although the etiology is probably multifactorial, the physiological effects of androgens are one possible reason that may explain these sex-specific differences in outcomes. There are at least two plausible mechanisms by which androgens may drive clinical outcomes in COVID-19. The first possible mechanism is linked to the expression of TMPRSS2, a cellular co-receptor required for SARS-CoV-2 infection (Hoffmann et al. 2020). The second possibility is androgen-driven immune modulation. Androgen regulation of the immune response may also partake in notable geographic variations in COVID-19associated clinical outcomes. Here, we discuss these possible mechanistic scenarios by learning from examples of androgen manipulation in prostate cancer and other disease processes.

SARS-CoV-2 viral entry is known to require two host cellular proteins (Hoffmann et al. 2020). First, the virus uses angiotensin converting enzyme-2 (ACE2) to enter into the host cell. Second, the viral spike protein is primed by the TMPRSS2 protease. Separate from viral infections, TMPRSS2, in fact, has a widely recognized role in prostate cancer pathogenesis, as approximately half of all tumors harbor a translocation that places the TMPRSS2 regulatory element in front of an ETS-family oncogene (Tomlins et al. 2005). The androgen-regulated nature of TMPRSS2 is what permits testosterone or dihydrotestosteronedriven oncogene expression in this scenario via the androgen receptor (AR) (Dai et al. 2017). In part, because of its oncogene-driving function, TMPRSS2 now serves as a canonical readout of AR-dependent transcription in prostate cancer models and tissues. While benign prostate and prostate cancer are clearly androgen-regulated tissues, this is not as clearly the case for pulmonary tissues. However, there are pulmonary disease processes, including asthma as one example, in which there are sexdependent differences in clinical outcomes and severity (Zein \& Erzurum 2015). TMPRSS2 is regulated by both androgens and glucocorticoids in a lung-derived cell line model (Mikkonen et al. 2010). Nevertheless, it is not known if TMPRSS2 expression in the normal human lung is regulated by androgens in physiological settings. If the answer is yes, and TMPRSS2 suppression impedes viral entry or activation, inhibition of (gonadal +/- adrenal) androgen synthesis or direct AR blockade with prostate cancer therapies, including enzalutamide or apalutamide, should be tested clinically.

Androgen modulation of the immune response is the second possible mechanism that may drive clinical outcomes by way of a compromised antiviral immune response to SARS-CoV-2. Generally, androgens have an immune suppressive effect. This is made apparent by several lines of evidence. First, women are disproportionately affected with inflammatory disease (c) 2020 Society for Endocrinology Published by Bioscientifica Ltd. Printed in Great Britain 
processes compared to men. For example, in the case of asthma, boys generally have worse asthma than girls, and a sex switch occurs after puberty with a surge of gonadal sex steroids, with better outcomes in men and worsening severity in women (DeBoer et al. 2018). Second, gonadal testosterone deprivation (i.e. medical or surgical castration) has immune stimulatory effects (Drake et al. 2005). Third, suppressed peripheral tissue availability of potent androgens synthesized from adrenal precursor steroids is associated with worse clinical outcomes in inflammatory disease (Zein et al. 2020).

This last line of evidence is worth expanding because it may relate to geographical variations in androgenassociated clinical outcomes. In addition to the gonadal source for androgens, the adrenal reticularis synthesizes and secretes abundant, but not directly active, androgens in the form of dehydroepiandrosterone (DHEA) and DHEA-sulfate. DHEA is converted to potent androgens in peripheral tissues in a pathway that is initiated and

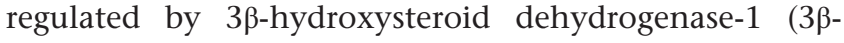
HSD1; encoded by HSD3B1) (Auchus \& Sharifi 2020). There are two major known functional forms of HSD3B1 that correspond to two different human alleles (Chang et al. 2013, Sabharwal \& Sharifi 2019). The adrenalrestrictive $H S D 3 B 1(1245 \mathrm{~A})$ allele encodes for an enzyme that is rapidly degraded and limits conversion from DHEA to downstream potent androgens. In contrast, the adrenalpermissive HSD3B1(1245C) allele encodes for an enzyme that is resistant to degradation, resulting in high steady-

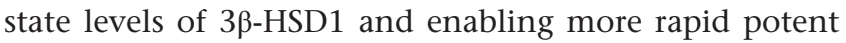
androgen synthesis from DHEA. Adrenal-permissive and adrenal-restrictive HSD3B1 allele inheritance confer clinically significant phenotypes as is most clearly evident by multiple studies of prostate cancer treated with medical castration, in which rapid extragonadal androgen synthesis enables more rapid progression to castrationresistant prostate cancer (CRPC) and slower synthesis is linked to delayed progression to CRPC, respectively (Hearn et al. 2020).

Do HSD3B1 alleles and their consequences on peripheral adrenal androgen metabolism confer immune regulation phenotypes? The answer appears to be yes. In low DHEA and DHEA-sulfate physiological states (in this case, exogenous glucocorticoid administration which suppresses DHEA and DHEA-sulfate by 70\%), HSD3B1 genotype correlates with clinical outcomes in two cohorts with severe asthma (Zein et al. 2020). Specifically, adrenalrestrictive HSD3B1 allele inheritance, which impairs potent androgen synthesis, is associated with worsened outcomes in asthma as assessed by multiple clinical Printed in Great Britain measures and absolute neutrophil count (Zein et al. 2020). This observation is consistent with an androgen-mediated immune suppressive effect. Stress and/or infection may also lead to low adrenal androgens in circulation, particularly in DHEA-sulfate (Arlt et al. 2006, Foster et al. 2020). The asthma data discussed above suggests that divergent functions of HSD3B1 alleles may become phenotypically clear in the setting of adrenal androgen suppression, in which the substrate for $3 \beta$-HSD1 becomes limiting, specifically for the enzyme encoded by the adrenal-restrictive $H S D 3 B 1$ allele.

Interestingly, Italy and Spain, European countries most severely affected by COVID-19 at this time, are places that have the highest frequency of the adrenalpermissive HSD3B1 allele in the general population, as per the 1000 Genomes Project (Sabharwal \& Sharifi 2019). Is this attributable, in part, to an immune suppressive role of augmented androgen synthesis with inheritance of the adrenal-permissive HSD3B1 allele? To test this directly, germline HSD3B1 information should be interrogated in affected patients.

A broad range of clinical approaches are being deployed against COVID. They range from blockade of ACE2, a key binding site in the lungs, to antimalarial drugs and standard antiviral agents. Observations about the role of TMPRSS2 and its known androgen dependence have prompted questions arising from prostate cancer treatment paradigms. Potential strategies range from evaluating the therapeutic potential of medical castration to blockade of the androgen receptor through available oral agents.

Novel therapies targeting the androgen receptor transformed outcomes of prostate cancer patients in the last decade. These novel, highly potent AR antagonists are enriched for activity against an amplified androgen receptor emergent through treatment-mediated selection pressure and are often accompanied by structural variants capable of ligand-independent agonism. It is unlikely that such adaptations exist in alveolar epithelial cells, or that such potent approaches would be necessary. It is not known whether pharmacological blockade of the androgen receptor or interrupting the luteinizing hormone releasing hormone axis, or both, is optimal in this setting. Such questions are the goal of planned clinical investigations.

An anti-COVID approach targeting androgenmediated TMPRSS2 expression requires a more pliable approach than prostate cancer strategies. For one, COVID is an acute illness that evolves rapidly through immediate post exposure, symptom onset and lethal ARDS. 
An AR-targeted approach may exert benefit only in one of these phases, most likely early onset. Testing this will require early detection of COVID infection and targeting the receptor, as later in the disease course such interventions may be overwhelmed by the inflammatory process. Careful consideration of patient selection is critical to adequately assess this interaction and therapeutic intervention.

\section{Declaration of interest}

Nima Sharifi has been a consultant for Celgene and Charles Ryan has been an adviser for Bayer. Cleveland Clinic has patents on HSD3B1.

\section{Funding}

This work was supported by grants from the National Cancer Institute (R01CA172382, R01CA190289, and R01CA236780) and the Prostate Cancer Foundation.

\section{References}

Arlt W, Hammer F, Sanning P, Butcher SK, Lord JM, Allolio B, Annane D \& Stewart PM 2006 Dissociation of serum dehydroepiandrosterone and dehydroepiandrosterone sulfate in septic shock. Journal of Clinical Endocrinology and Metabolism 91 2548-2554. (https://doi. org/10.1210/jc.2005-2258)

Auchus RJ \& Sharifi N 2020 Sex hormones and prostate cancer. Annual Review of Medicine 71 33-45. (https://doi.org/10.1146/annurevmed-051418-060357)

Cai H 2020 Sex difference and smoking predisposition in patients with COVID-19. Lancet: Respiratory Medicine 8 e20. (https://doi. org/10.1016/S2213-2600(20)30117-X)

Chang KH, Li R, Kuri B, Lotan Y, Roehrborn CG, Liu J, Vessella R, Nelson PS, Kapur P, Guo X, et al. 2013 A gain-of-function mutation in DHT synthesis in castration-resistant prostate cancer. Cell $\mathbf{1 5 4}$ 1074-1084. (https://doi.org/10.1016/j.cell.2013.07.029)

Dai C, Heemers H \& Sharifi N 2017 Androgen signaling in prostate cancer. Cold Spring Harbor Perspectives in Medicine $\mathbf{7}$ a030452. (https:// doi.org/10.1101/cshperspect.a030452)

Deboer MD, Phillips BR, Mauger DT, Zein J, Erzurum SC, Fitzpatrick AM, Gaston BM, Myers R, Ross KR, Chmiel J, et al. 2018 Effects of endogenous sex hormones on lung function and symptom control in adolescents with asthma. BMC Pulmonary Medicine 18 58. (https:// doi.org/10.1186/s12890-018-0612-x)

Drake CG, Doody AD, Mihalyo MA, Huang CT, Kelleher E, Ravi S, Hipkiss EL, Flies DB, Kennedy EP, Long M, et al. 2005 Androgen ablation mitigates tolerance to a prostate/prostate cancer-restricted antigen. Cancer Cell 7 239-249. (https://doi.org/10.1016/j. ccr.2005.01.027)

Foster MA, Taylor AE, Hill NE, Bentley C, Bishop J, Gilligan LC, Shaheen F, Bion JF, Fallowfield JL, Woods DR, et al. 2020 Mapping the steroid response to major trauma from injury to recovery: a prospective cohort study. Journal of Clinical Endocrinology and Metabolism 105 dgz302. (https://doi.org/10.1210/clinem/dgz302)

Grasselli G, Zangrillo A, Zanella A, Antonelli M, Cabrini L, Castelli A, Cereda D, Coluccello A, Foti G, Fumagalli R, et al. 2020 Baseline characteristics and outcomes of 1591 patients infected with SARSCoV-2 admitted to ICUs of the Lombardy Region, Italy. JAMA [epub]. (https://doi.org/10.1001/jama.2020.5394)

Hearn JWD, Sweeney CJ, Almassi N, Reichard CA, Reddy CA, Li H, Hobbs B, Jarrard DF, Chen YH, Dreicer R, et al. 2020 HSD3B1 genotype and clinical outcomes in metastatic castration-sensitive prostate cancer. JAMA Oncology 6 e196496. (https://doi.org/10.1001/ jamaoncol.2019.6496)

Hoffmann M, Kleine-Weber H, Schroeder S, Kruger N, Herrler T, Erichsen S, Schiergens TS, Herrler G, Wu NH, Nitsche A, et al. 2020 SARS-CoV-2 cell entry depends on ACE2 and TMPRSS2 and is blocked by a clinically proven protease inhibitor. Cell $181271 . e 8-$ 280.e8. (https://doi.org/10.1016/j.cell.2020.02.052)

Mikkonen L, Pihlajamaa P, Sahu B, Zhang FP \& Janne OA 2010 Androgen receptor and androgen-dependent gene expression in lung. Molecular and Cellular Endocrinology 317 14-24. (https://doi. org/10.1016/j.mce.2009.12.022)

Moalem S 2020 Why are so many more men dying from coronavirus? New York Times. (available at: https://www.nytimes.com/2020/04/02/ opinion/coronavirus-men-women.html)

Sabharwal N \& Sharifi N 2019 HSD3B1 genotypes conferring adrenalrestrictive and adrenal-permissive phenotypes in prostate cancer and beyond. Endocrinology 160 2180-2188. (https://doi.org/10.1210/ en.2019-00366)

Tomlins SA, Rhodes DR, Perner S, Dhanasekaran SM, Mehra R, Sun XW, Varambally S, Cao X, Tchinda J, Kuefer R, et al. 2005 Recurrent fusion of TMPRSS2 and ETS transcription factor genes in prostate cancer. Science 310 644-648. (https://doi.org/10.1126/ science.1117679)

Zein JG \& Erzurum SC 2015 Asthma is different in women. Current Allergy and Asthma Reports 15 28. (https://doi.org/10.1007/s11882015-0528-y)

Zein J, Gaston B, Bazeley P, DeBoer MD, Igo RP, Bleecker ER, Meyers D, Comhair S, Marozkina NV, Cotton C, et al. 2020 HSD3B1 genotype identifies glucocorticoid responsiveness in severe asthma. PNAS 117 2187-2193. (https://doi.org/10.1073/pnas.1918819117)

Received in final form 10 April 2020

Accepted 17 April 2020

Accepted Manuscript published online 17 April 2020 (c) 2020 Society for Endocrinology Published by Bioscientifica Ltd. Printed in Great Britain 